\title{
Influência do Pré-aquecimento Indutivo Localizado sobre Características Metalúrgicas de Juntas Soldadas
}

\author{
William Todendi Dutra ${ }^{1}$, Ivan Guerra Machado ${ }^{1}$ \\ 1 Universidade Federal do Rio Grande do Sul - UFRGS, Laboratório de Soldagem \& Técnicas Conexas, Programa de \\ Pós-graduação em Engenharia de Minas, Metalúrgica e de Materiais - PPGE3M, Porto Alegre, RS, Brasil.
}

Recebido: 13 Set., 2017

Aceito: 08 Nov., 2017

E-mails: william.dutra@ufrgs.br(WTD), welder@ufrgs.br (IGM)
Resumo: Uma das finalidades do pré-aquecimento na soldagem é reduzir a taxa de resfriamento da junta a ser soldada, com consequente minimização da formação de fases frágeis. Esta prática é usualmente executada em uma região relativamente extensa entorno da junta, eventualmente causando alterações indevidas nas propriedades mecânicas e metalúrgicas do metal base, além de desperdiçar energia e tempo. Desta forma, neste trabalho foi utilizado um equipamento de aquecimento indutivo para aquecer localmente a zona a ser soldada, visando avaliar a microestrutura formada e o perfil de durezas encontrado para os parâmetros variados. A utilização do pré-aquecimento se mostrou efetiva na redução da taxa de resfriamento e consequentemente a proporção de fases frágeis e microdureza máxima das juntas.

Palavras-chave: Soldagem; Aquecimento indutivo; Pré-aquecimento.

\section{Influence of Localized Induction Preheating on Metallurgical Characteristics of Welded Joints}

\begin{abstract}
One of the purposes of welding preheating is to decrease cooling rate of the joint to be welded, with consequent minimization of brittle phases formation. This practice is usually performed in a relatively large area around the joint, eventually causing undue changes in base metal mechanical and metallurgical properties, beyond to waste energy and time. Therefore, in this work an inductive heating equipment was used to locally heat the zone to be welded, aiming to evaluate the formed microstructure and the hardness profile found for the varied parameters. The use of preheating was effective in reducing cooling rates and consequently the proportion of brittle phases and maximum microhardness of the welded joint.
\end{abstract}

Key-words: Welding; Inductive heating; Preheating.

\section{Introdução}

O ciclo térmico ao qual é submetido um aço tem influência muito importante em suas propriedades mecânicas. Essas variações de temperaturas em relação ao tempo, normalmente expressos na forma de taxas, podem alterar a forma como os metais se arranjam em sua estrutura cristalina, a qual tem relação direta nas propriedades físicas da peça que fazem parte. São então fatores cruciais a serem controlados durante o processamento do produto a temperatura a que este está submetido, bem como o tempo em que permanece nessa temperatura e principalmente o quão alta é a taxa de resfriamento nos diferentes pontos do material.

No caso da soldagem, a energia de soldagem $E(\mathrm{~kJ} / \mathrm{mm})$ e a temperatura de pré-aquecimento são as fontes de calor que governam o aumento de temperatura em uma junta, enquanto que a condutividade térmica $k\left(\mathrm{~J} / \mathrm{mm}^{*} \mathrm{~s}^{\left.*{ }^{\circ} \mathrm{C}\right)}\right.$, a densidade $\rho\left(\mathrm{kg} / \mathrm{m}^{3}\right)$ e calor específico $c\left(\mathrm{~J} / \mathrm{kg}^{* \circ} \mathrm{C}\right)$ do material atenuam o aumento da temperatura e comandam a dissipação do calor. A taxa de resfriamento é uma consequência do quanto o material recebe de calor e quanto ele consegue dissipar por unidade de tempo.

Em soldagem, a utilização de pré-aquecimento está intimamente ligado à redução das taxas de resfriamento da região soldada. É utilizado principalmente em aços tratados termicamente ou termomecanicamente, ou naqueles que tendem a formar trinca induzida por hidrogênio, já que nesse caso são mantidas temperaturas onde as taxas de difusão do hidrogênio são significativamente maiores que aquelas em temperatura ambiente [1].
Este e um artigo publicado em acesso aberto (Open Access)
sob a licença Creative Commons Attribution Non-Commercis que permite uso, distribuicão e reprodução em qualquer meio, sem restriçōes desde que sem fins comerciais e que 0 trabalho original seja corretamente citado. 
A necessidade de pré-aquecimento aumenta com o aumento da espessura da seção a ser soldada, com o maior nível de constrangimento da solda e maior conteúdo de carbono e/ou elemento de liga presente no aço, e por fim com a quantidade de hidrogênio difusível do metal de solda [2,3].

Duas formas são as mais comuns de se fazer o pré-aquecimento: com chama através de maçaricos oxigás, ou pela utilização de mantas de aquecimento resistivo. Nestes casos, as áreas aquecidas são grandes e não bem definidas, pois abrangem muito mais do que somente a área da solda. Este problema pode ser contornado em alguns casos, utilizando-se uma fonte de potência para aquecimento indutivo. Este tipo de equipamento gera calor de forma rápida, uniforme e localizada, o qual pode ser focado através de concentradores de fluxo magnético (um dos princípios do funcionamento desse tipo de aquecimento) diretamente e somente na região a ser soldada.

Jones et al. [4] cita que a estratégia de usar um sistema composto de soldagem com pré-aquecimento indutivo, visa incrementar consideravelmente a produtividade. Como o local a ser soldado alcança temperaturas próximas à fusão do metal a penetração é facilitada, reduzindo o número de passes, e como os gradientes de temperaturas ao longo da seção são menores, é possível reduzir ou até eliminar distorções de soldagem [5].

\section{Materiais e Métodos}

Foi planejada através de um projeto de experimentos uma grade de combinação dos fatores a serem variados, com a finalidade de se obter a maior quantidade de informações com um número mínimo de experimentos. Os parâmetros de soldagem permaneceram inalterados, enquanto eram variados a velocidade de soldagem entre $6 \mathrm{~mm} / \mathrm{s}$ e $12 \mathrm{~mm} / \mathrm{s}$ e a potência do equipamento de aquecimento indutivo entre $6 \mathrm{~kW}$ e $12 \mathrm{~kW}$. A soldagem foi realizada pelo processo MAG com arame ER70S- 6 de 1,2 mm de diâmetro, gás de proteção $25 \% \mathrm{CO}_{2}+75 \% \mathrm{Ar}$, tensão de $30 \mathrm{~V}$ e distância do bico do contato até a peça de $18 \mathrm{~mm}$, acarretando em uma corrente de cerca de $245 \mathrm{~A}$. Em estudo anterior [6] foi constatado que os parâmetros de montagem distância indutor-peça (dip) e a distância tocha-indutor (dti), vistos na Figura 1, não afetaram significativamente a geometria do cordão de solda; então nessa série de experimentos foram mantidos os valores de dip e dti iguais a 2,5 $\mathrm{mm}$ e $10 \mathrm{~mm}$ respectivamente. A cota 'li' representa o comprimento fixo do indutor, igual a $60 \mathrm{~mm}$. Vale salientar que valores muito maiores para as duas variáveis podem afetar a temperatura na qual a peça atinge localmente como pré-aquecimento, porém na faixa estudada (até três vezes maiores) não foi observada diferença significativa.

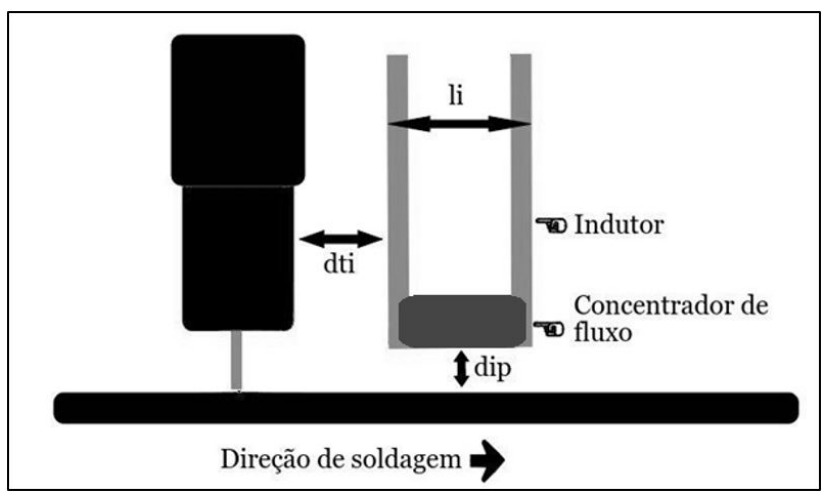

Figura 1. Esquema da montagem em tandem de um sistema de soldagem MIG/MAG com pré-aquecimento indutivo localizado.

As temperaturas de pré-aquecimento variaram de acordo com a potência e velocidade de soldagem. Pode ser visto na Tabela 1 uma relação entre os parâmetros variados e as temperaturas máximas alcançadas, adquiridas através de uma termocâmera com capacidade de medição até $1200^{\circ} \mathrm{C}$ e resolução de $\pm 2{ }^{\circ} \mathrm{C}$, medida em toda extensão do corpo de prova.

Foi utilizado o aço AISI 1045, na forma de chapas com 7,9 mm de espessura, por este apresentar suscetibilidade à formação de fases frágeis e por já ter sido bastante estudado na literatura. A composição química deste aço pode ser vista na Tabela 2. Segundo as normas ASTM A1005/A-00 [7] e ASME B16.49-2000 [8], a taxa de resfriamento 
Tabela 1. Relação da temperatura alcançada na peça com os parâmetros de potência de aquecimento indutivo e velocidade de soldagem.

\begin{tabular}{ccc}
\hline Potência $(\mathbf{k W})$ & $\begin{array}{c}\text { Velocidade de } \\
\text { Soldagem }(\mathbf{m m} / \mathbf{s})\end{array}$ & $\begin{array}{c}\text { Temperatura } \\
\text { alcançada na peça }\left({ }^{\circ} \mathbf{C}\right)\end{array}$ \\
6 & 12 & 167 \\
6 & 6 & 253 \\
12 & 12 & 418 \\
12 & 6 & 590 \\
\hline
\end{tabular}

Tabela 2. Composição química do aço AISI 1045 utilizado nos experimentos.

\begin{tabular}{lccccc}
\hline $\begin{array}{c}\text { Elemento } \\
\text { Químico }\end{array}$ & $\mathbf{C}$ & $\mathbf{M n}$ & Si & S & $\mathbf{P}$ \\
\hline \% massa & 0,45 & 0,84 & 0,17 & $<0,02$ & $<0,02$ \\
\hline
\end{tabular}

para que um aço não forme fases frágeis em sua Zona Afetada pelo Calor (ZAC) e assim não corra o risco de ocorrer fratura na junta, pode ser calculada baseada no Carbono Equivalente (CEn) do aço. As normas citadas fazem o cálculo de CEn através da Equação 1.

$$
C E n=C+f(c)\left\{\frac{S i}{24}+\frac{M n}{6}+\frac{C u}{15}+\frac{N i}{20}+\frac{(C r+M o+N b+V)}{5}\right\}
$$

Onde a função $f(C)=0,5+0,25$ tanh $\{20(C-0,12)\}$. Segundo Yurioka e Kasuya [9] isso acarreta em temperaturas de pré-aquecimento de 100 C em condições normais de soldagem, a 140 C em condições de reparo para este aço, na faixa de energias de soldagem utilizadas.

As temperaturas alcançadas nos experimentos são significativamente superiores àquelas sugeridas pelas normas citadas, porém é imperativo lembrar que os pré-aquecimentos mencionados nas normas geralmente abrangem uma largura total mínima de cerca de $150 \mathrm{~mm}$, sendo desejável uma largura de $200 \mathrm{~mm}$ segundo Yurioka e Kasuya [9]. No caso do pré-aquecimento indutivo localizado utilizado neste estudo, operando a $111 \mathrm{kHz}$, com um indutor de 9,5 $\mathrm{mm}$ de diâmetro, comprimento li=60 $\mathrm{mm}$ e distância até a peça (dip) de 2,5 $\mathrm{mm}$, a largura da região aquecida é de cerca de $5 \mathrm{~mm}$ com uma penetração de aquecimento de $3 \mathrm{~mm}$. Como a distância entre indutor e tocha de soldagem é de $10 \mathrm{~mm}$, deve se considerar a queda de temperatura entre o deslocamento. Foi simulado através de um software de simulação física [10] a etapa de pré-aquecimento localizado e a dissipação do calor para um ponto na superfície, distante transversalmente $9 \mathrm{~mm}$ do centro da solda, onde foi possível medir com termopares o ciclo térmico apenas na condição sem pré-aquecimento (por risco de queima do equipamento quando utilizado o sistema indutivo).

Pode ser visto na Figura 2 a curva de aquecimento e resfriamento para o caso onde a temperatura máxima foi de $418^{\circ} \mathrm{C}$ com velocidade de soldagem igual a $12 \mathrm{~mm} / \mathrm{s}$, o que acarreta em um tempo para a queda de temperatura de cerca de $0,83 \mathrm{~s}$, devido a distância 'dti' a ser percorrida na velocidade utilizada. No detalhe da imagem a seção transversal do modelo simulado com T apontando o local de simulação da queda de temperatura e o semicírculo claro como a fonte de calor. $O$ tempo de fonte de calor ativa nesse caso foi de $5 \mathrm{~s}$, obtido dividindo o comprimento do indutor 'li' pela velocidade de soldagem ' $V$ s'. Logo, a temperatura de pré-aquecimento efetiva é aquela traçada no gráfico com tempo igual a 5,83 s, e neste caso é igual a $277^{\circ} \mathrm{C}$. A Tabela 3 mostra as temperaturas máximas de aquecimento indutivo localizado medidas pelas termocâmera e a temperatura efetiva obtida das simulações, equivalentes à temperatura de pré-aquecimento $\mathrm{T}_{0}$.

As taxas de resfriamento calculadas segundo Rosenthal [11] consideram o metal resfriando até a temperatura de pré-aquecimento, pois leva em consideração uma região grande em torno da junta assim como o recomendado pelas normas [7,8]. A Equação 2, deduzida por Rosenthal considera a condutividade térmica do material ( $\mathrm{k}$ ), a energia de soldagem (E) e a temperatura de pré-aquecimento $\left(T_{0}\right)$ para extração de calor em 3 dimensões. $T_{r}$ é a temperatura 


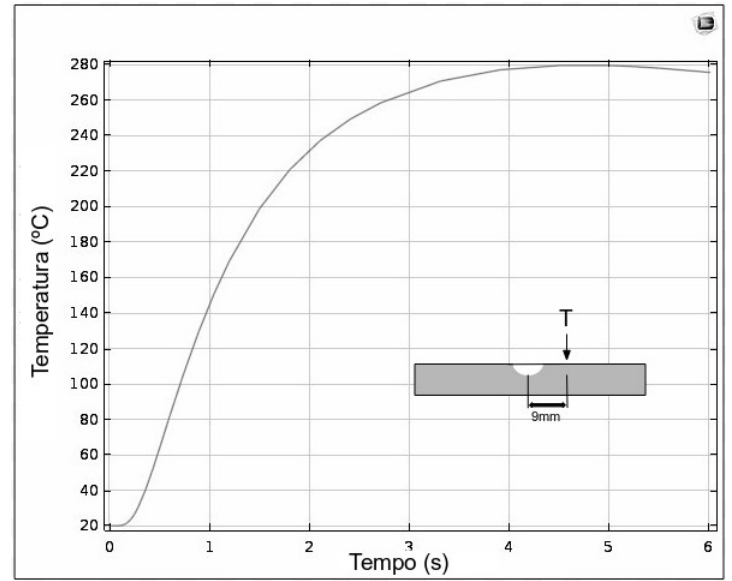

Figura 2. Simulação do aquecimento de um ponto superficial distante $9 \mathrm{~mm}$ da linha central de uma fonte de calor semi-elipsoide com $5 \mathrm{~mm}$ largura e $3 \mathrm{~mm}$ de penetração.

Tabela 3. Temperaturas máximas medidas e temperatura efetiva simulada.

\begin{tabular}{lllll}
\hline Temperatura Máxima $\left({ }^{\circ} \mathrm{C}\right)$ & 167 & 253 & 418 & 590 \\
Temperatura Efetiva Simulada no ponto T $\left({ }^{\circ} \mathrm{C}\right)$ & 126 & 221 & 277 & 464 \\
\hline
\end{tabular}

de referência na qual se deseja calcular a taxa de resfriamento, usualmente $550^{\circ} \mathrm{C}$. Na Tabela 4 são mostradas as taxas calculadas utilizando a Equação 2 para as temperaturas $\mathrm{T}_{0}$ simuladas da Tabela 3 no ponto T da Figura 2.

$$
\frac{d T}{d t}=-\frac{2 \prod k\left(T_{r}-T_{0}\right) 2}{E}
$$

Tabela 4. Taxas de resfriamento $\left({ }^{\circ} \mathrm{C} / \mathrm{s}\right)$ à $550^{\circ} \mathrm{C}$ calculadas pela Equação 2 para as temperaturas simuladas $\mathrm{T}\left({ }^{\circ} \mathrm{C}\right)$ e velocidade $\mathrm{Vs}(\mathrm{mm} / \mathrm{s})$ no ponto $\mathrm{T}$.

\begin{tabular}{cccccc}
\hline $\mathbf{T}(\mathbf{1 2 6}) \mathbf{V s}(\mathbf{1 2})$ & $\mathbf{T}(\mathbf{2 2 1}) \mathbf{V s}(\mathbf{6})$ & $\mathbf{T}(\mathbf{2 7 7}) \mathbf{V s}(\mathbf{1 2})$ & $\mathbf{T}(\mathbf{4 6 4}) \mathbf{V s}(\mathbf{6})$ & $\mathbf{T}(\mathbf{0}) \mathbf{V s}(\mathbf{6})$ & $\mathbf{T}(\mathbf{0}) \mathbf{V s}(\mathbf{1 2})$ \\
109,7 & 33,7 & 45,5 & 2,32 & 94,2 & 184,6 \\
\hline
\end{tabular}

As taxas são atenuadas pelo pré-aquecimento e é possível notar que a velocidade de soldagem Vs comanda esse efeito, sendo as maiores taxas de resfriamento aquelas que acompanham a maior Vs. Comparando a taxa para temperatura de pré-aquecimento de $126^{\circ} \mathrm{C}$ e Vs=12 mm/s (segunda coluna da Tabela 3) com a taxa sem pré-aquecimento e $\mathrm{Vs}=6 \mathrm{~mm} / \mathrm{s}$ da sexta coluna é possível ver que apesar da temperatura maior a velocidade é dominante às taxas por reduzir a energia $\mathrm{E}$ da Equação 2.

\subsection{Análise metalúrgica}

Como mencionado, o ciclo térmico ao qual é submetida uma junta soldada é de grande importância sobre as propriedades mecânicas da estrutura da qual faz parte. Taxas muito altas de resfriamento produzem fases frágeis. É usual traçar o perfil de microdurezas para uma junta soldada a fim de analisar as máximas microdurezas, geralmente encontradas na ZAC. Para cada junta soldada foram retirados dois corpos de prova transversais à linha de solda e feita a preparação metalográfica convencional com lixamento manual em lixas de granulometria de 100 a 1200 mesh, com posterior polimento utilizando alumina $0,5 \mu \mathrm{m}$, e ataque químico com reagente Nital $2 \%$ ( $2 \%$ de ácido nítrico diluído em álcool anidro) sendo as amostras observadas sob microscópio ótico em aumentos de 50 a 1000 vezes. Foram traçados os perfis de microdureza e Tabelada a máxima microdureza para cada corpo de 
prova, com os experimentos feitos em duplicata para fins estatísticos. Também foram feitas macro e micrografias para realização da conferência entre microestrutura e microdureza. A Figura 3 mostra o local onde foi traçado o perfil de microdurezas, a região de medição de ciclo térmico (para os casos sem pré-aquecimento indutivo) e a região de análise microestrutural que engloba toda a extensão da ZAC.

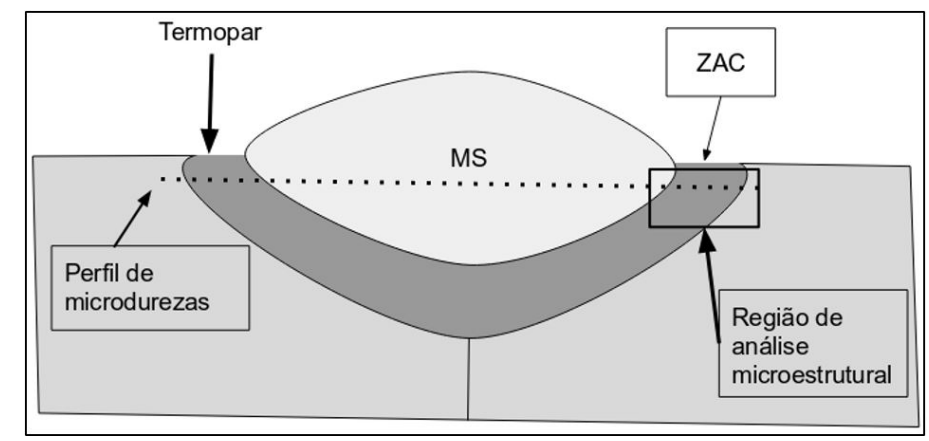

Figura 3. Esquema das regiões analisadas em termos de microdureza ( $1 \mathrm{~mm}$ abaixo da superfície), ciclo térmico e microestrutura.

\section{Resultados e Discussão}

Foi retirada uma amostra do metal base para avaliação da microestrutura e microdureza. Na Figura 4 pode ser visto a micrografia do AISI 1045 o qual apresenta microestrutura constituída de perlita fina com ferrita em contorno de grão. A dureza da amostra é de 200 HV.

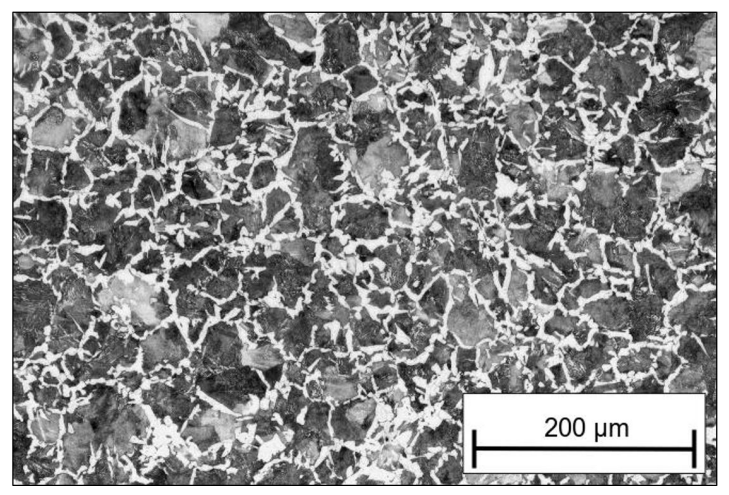

Figura 4. Micrografia do aço AISI 1045 constituída de perlita fina com ferrita em contorno de grão. Reagente Nital $2 \%$.

Foram feitos perfis de microdureza Vickers com carga de 0,5 kgf, tempo de indentação de 10 s e espaçamento de 0,3 $\mathrm{mm}$ entre medidas, em uma linha transversal ao cordão de solda, $1 \mathrm{~mm}$ abaixo da superfície conforme Figura 3. As máximas durezas podem ser vistas na Tabela 5.

Tabela 5. Dureza máxima (HV 0,5) encontrada no perfil das amostras para as diferentes situações de potência de pré-aquecimento e velocidade de soldagem.

\begin{tabular}{ccccc}
\hline & & \multicolumn{3}{c}{ Potência de Aquecimento indutivo (kW) } \\
\cline { 3 - 5 } & & $\mathbf{0}$ & $\mathbf{6}$ & $\mathbf{1 2}$ \\
Velocidade de Soldagem & $\mathbf{6}$ & 315 & 298 & 297 \\
$(\mathbf{m m} / \mathbf{s})$ & $\mathbf{9}$ & 335 & 297 & 308 \\
& $\mathbf{1 2}$ & 401 & 350 & 339 \\
\hline
\end{tabular}


Nota-se a redução da dureza com o aumento da potência de pré-aquecimento indutivo. Porém, é mais significativa a redução de dureza entre a utilização ou não do pré-aquecimento, do que no aumento da potência de pré-aquecimento. A Figura 5 mostra o perfil de dureza traçado na amostra soldada com potência de pré-aquecimento de $12 \mathrm{~kW}$ e velocidade de soldagem de $6 \mathrm{~mm} / \mathrm{s}$, sendo os picos de dureza inferiores a $300 \mathrm{HV}$ notados na região de crescimento de grãos da ZAC. Na Figura 6 é mostrado o perfil traçado para a amostra sem pré-aquecimento (potência igual a zero) e com velocidade de soldagem igual a $12 \mathrm{~mm} / \mathrm{s}$, onde notam-se novamente os picos de dureza na zona de crescimento de grãos da ZAC, sendo a dureza superior a $300 \mathrm{HV}$ em boa parte da ZAC.

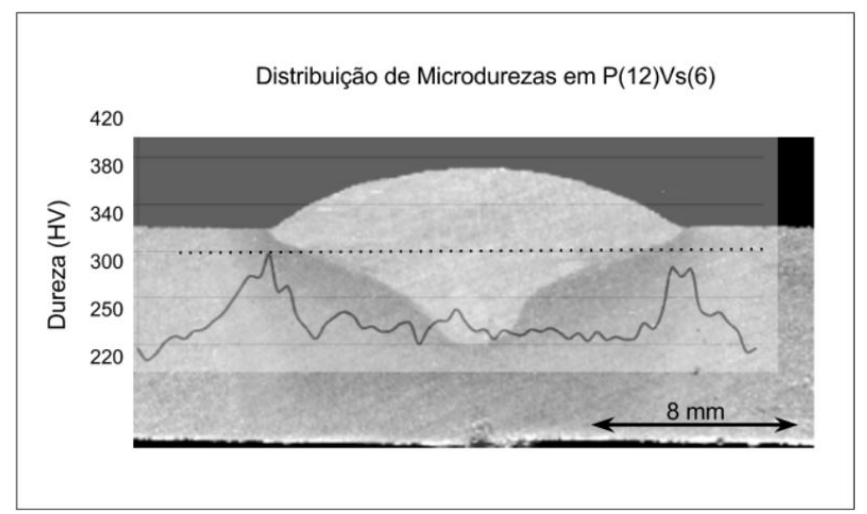

Figura 5. Perfil de microdureza traçado sobre macrografia da junta soldada com potência de pré-aquecimento indutivo de $12 \mathrm{~kW}$ e velocidade de soldagem de $6 \mathrm{~mm} / \mathrm{s}$. Linha tracejada marca o local de medição de microdureza.

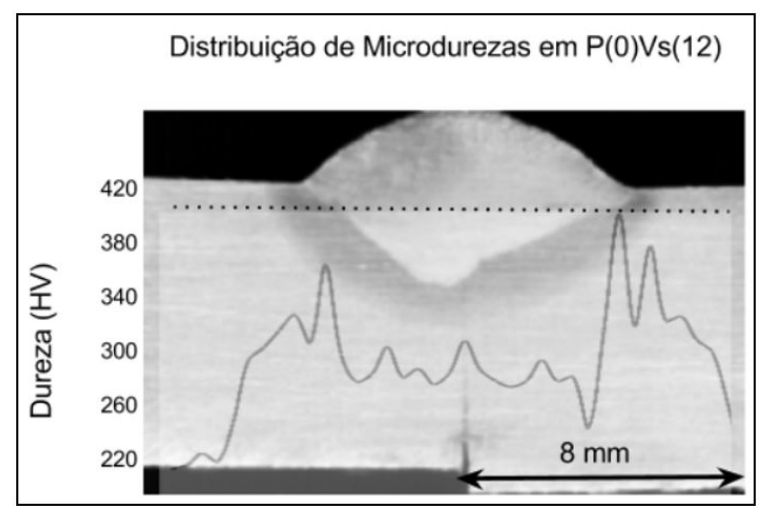

Figura 6. Perfil de dureza traçado sobre macrografia da junta soldada sem pré-aquecimento indutivo e velocidade de soldagem de $6 \mathrm{~mm} / \mathrm{s}$. Linha tracejada marca o local de medição de microdureza.

A menor taxa de resfriamento neste aço para a formação de $100 \%$ de martensita é de $110^{\circ} \mathrm{C} / \mathrm{s}$ [12]. Para o AISI 1045 a máxima dureza possível é cerca de 615 HV, com 100\% de martensita. Na medição com termopares a $9 \mathrm{~mm}$ de distância da linha central da solda (representado na Figura 3), feita apenas nos casos sem aquecimento indutivo (por risco de danificar o equipamento de aquisição), a taxa de resfriamento para o caso de $\mathrm{Vs}=6 \mathrm{~mm} / \mathrm{s}$ [T(0)Vs(6)] foi de $101^{\circ} \mathrm{C} / \mathrm{s}$, porém como visto na Tabela 5 a dureza medida de $315 \mathrm{HV}$ é muito inferior ao patamar de $615 \mathrm{HV}$, apesar da diferença de apenas $9^{\circ} \mathrm{C} / \mathrm{s}$ entre as taxas. Isso se dá provavelmente pela incompleta austenitização da região, embora a amostra tenha atingido $836^{\circ} \mathrm{C}$, a mesma permaneceu apenas por um curto espaço de tempo à esta temperatura.

Foi observada toda extensão da ZAC conforme Figura 3, sendo a zona de crescimento de grãos a região crítica à formação de fases frágeis. Para o caso da soldagem sem pré-aquecimento com velocidade de soldagem de $12 \mathrm{~mm} / \mathrm{s}$ [T(0)Vs(12)], foi possível observar formação de ilhas de martensita (IM). A Figura 7 mostra uma visão geral da ZAC, sendo indicada a região de formação das fases frágeis (IM). A dureza dessas ilhas alcançou $550 \mathrm{HV}$, 


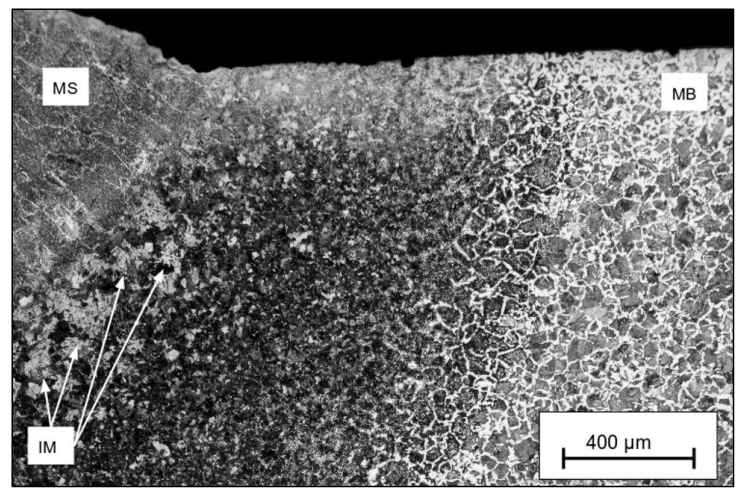

Figura 7. Micrografia mostrando desde o metal de solda (MS) até o metal base (MB) e indicando a região de formação das ilhas de martensita (IM). Reagente Nital $2 \%$.

podendo ser vistas na Figura 8 com maior aumento algumas delas. Nesta condição era esperado encontrar microestruturas martensíticas ou bainíticas devido a baixa energia de soldagem ocasionar altas taxas de resfriamento.

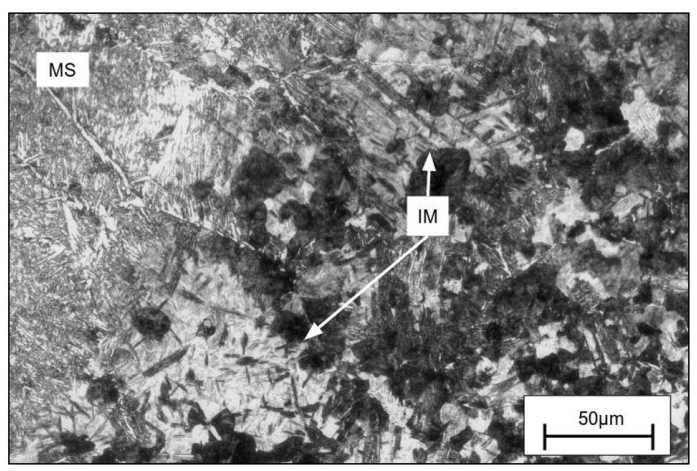

Figura 8. Micrografia de T(0)Vs(12) mostrando parcialmente o metal de solda (MS), ilhas de martensita (IM). Reagente Nital $2 \%$.

Apesar da utilização de pré-aquecimento indutivo, na situação T(126)Vs(12), que contava com uma potência de aquecimento de $6 \mathrm{~kW}$, pode ser visto na Figura 9 que o uso de temperaturas acima do recomendado não foi suficiente para evitar a formação de fases frágeis. A dureza máxima destas ilhas foi de 389 HV. Nota-se o começo de formação de ferrita em contorno de grãos, mais evidente próximo à escala da imagem. Na Figura 10 pode-se ver com mais detalhes a formação de provável bainita em matriz martensítica. A extensão da zona de formação de ilhas de martensita e/ou bainita em todos os casos, situou-se entre 330 e 350 um de distância da zona fundida, dentro da região de crescimento de grão da ZAC.

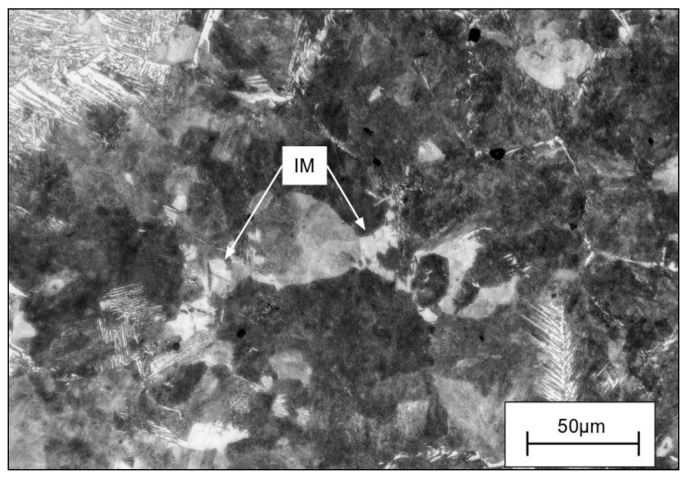

Figura 9. Micrografia de T(126)Vs(12) mostrando ilhas de martensita (IM). Reagente Nital 2\%. 


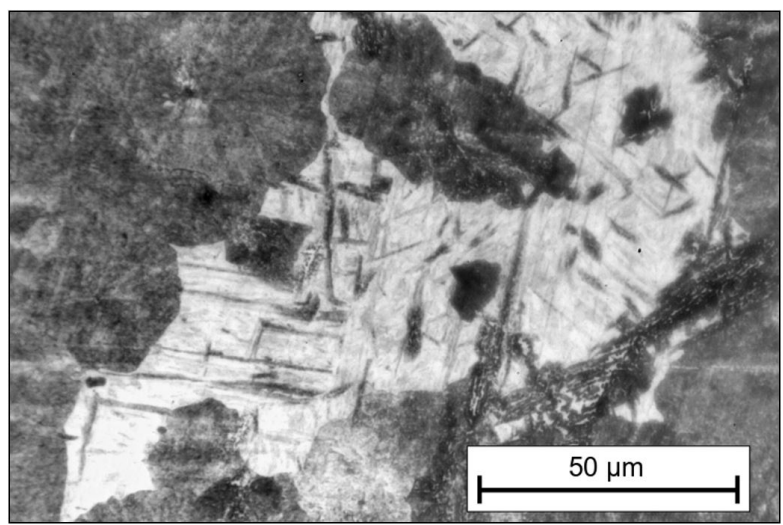

Figura 10. Micrografia de T(126)Vs(12) com foco nas ilhas de provável bainita em matriz martensítica. Reagente Nital $2 \%$.

Nas demais situações não houve formação de ilhas de martensita ou bainita. A microestrutura presente nestas foi predominante de perlita fina, assim como as regiões adjacentes às ilhas de martensita e bainita encontradas nas situações citadas anteriormente. A Figura 11 mostra a condição T(464)Vs(6) apresentada na Figura 5, onde as taxas de resfriamento foram baixas e as microdurezas ficaram abaixo dos $300 \mathrm{HV}$. Na imagem é possível ver uma microestrutura constituída de perlita fina e ferrita em contorno de grão. A Figura 12 aproxima a visão sobre a condição T(464)Vs(6), próximo à região preferencial à formação de fases frágeis, mostrando microestrutura perlítica fina sendo possível distinguir as lamelas de ferrita e cementita, e ferrita em contorno de grão.

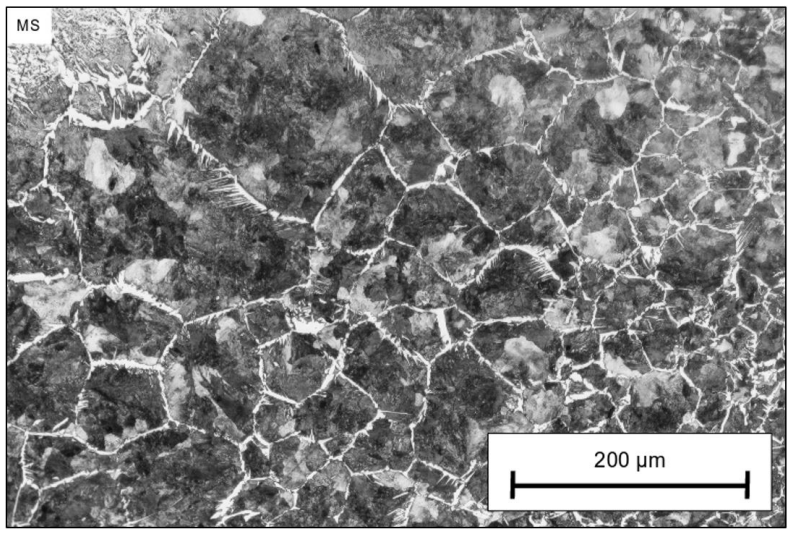

Figura 11. Micrografia de T(464)Vs(6) mostrando perlita fina e ferrita em contorno de grão. Reagente Nital $2 \%$.

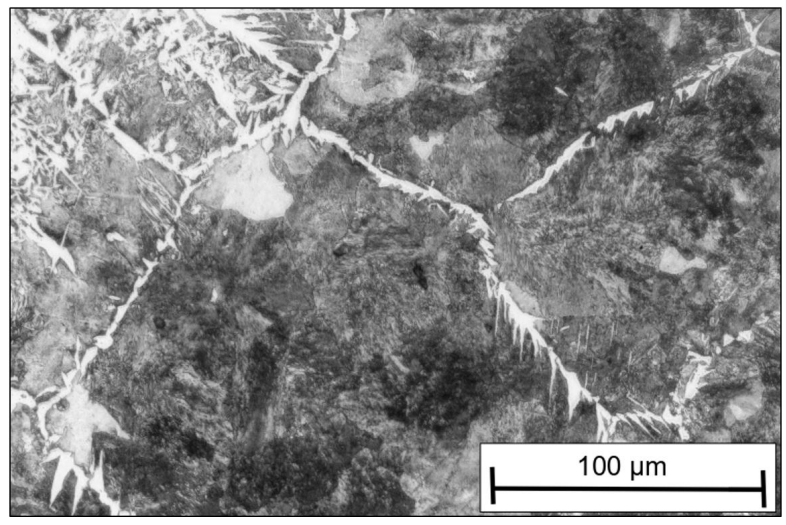

Figura 12. Micrografia de $\mathrm{T}(464) \mathrm{Vs}(6)$ mostrando perlita fina e ferrita em contorno de grão. Reagente Nital $2 \%$. 
Com o aumento da temperatura de pré-aquecimento foi favorecida a formação de ferrita em contorno de grão como mostrado na Figura 13 , que compara as condições de soldagem com pré-aquecimento de $126^{\circ} \mathrm{C}$ e $464^{\circ} \mathrm{C}$ respectivamente, e é possível notar o aumento de zonas claras entre grãos escuros (perlita).

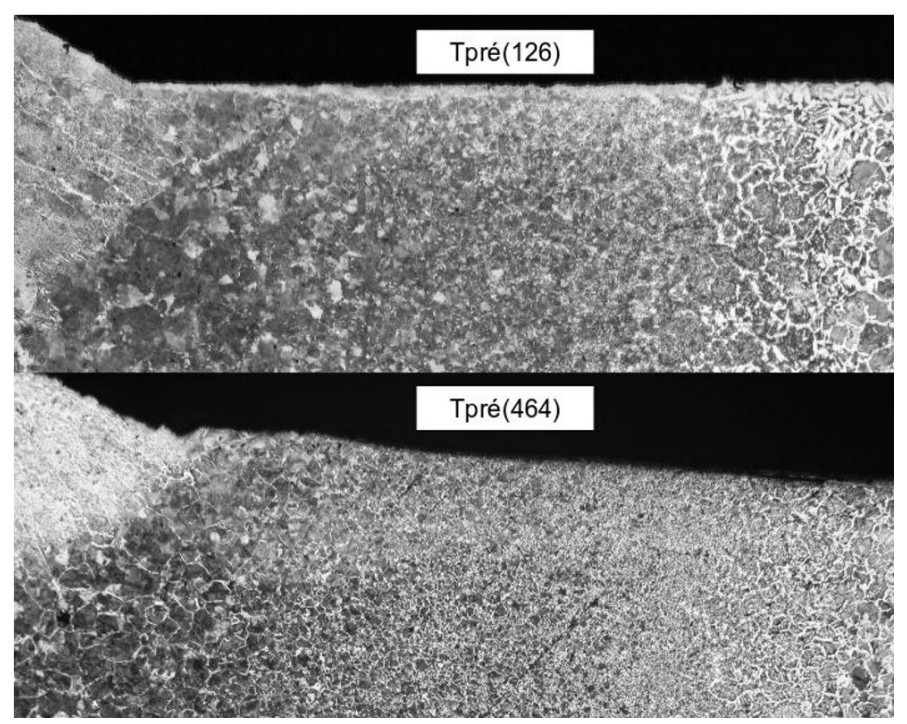

Figura 13. Micrografia comparativa entre a quantidade de ferrita em contorno de grão (regiões claras) formada com a maior temperatura de pré-aquecimento (Tpré). Reagente Nital $2 \%$.

\section{Conclusões}

Com o objetivo de estudar os efeitos dos parâmetros de velocidade de soldagem e potência de aquecimento indutivo, sobre as características metalúrgicas de juntas soldadas com o auxílio de um equipamento que realizasse pré-aquecimento localizado, comparando com os mesmos parâmetros de juntas soldadas sem pré-aquecimento, pode-se tecer as seguintes conclusões:

- Foi possível realizar a redução das taxas de resfriamento, acarretando na redução de durezas e consequentemente da formação de fases frágeis;

- A redução de durezas foi mais evidente entre a utilização ou não do pré-aquecimento, do que no aumento da temperatura de pré-aquecimento para este aço;

- A utilização de pré-aquecimento indutivo localizado foi capaz de reduzir a dureza entre $5 \%$ a $13 \%$ em comparação com sua não utilização;

- É possível perceber uma dominância da velocidade de soldagem sobre a taxa de resfriamento, ao passo de que esta reduz significativamente a energia de soldagem, concentrando a fonte de calor e aumentando os gradientes de temperaturas, que são a força motriz na extração do calor;

- Este sistema de soldagem aparentemente apresenta um bom resultado quanto à aplicação de pré-aquecimento em juntas soldadas de aços que necessitem deste preparo, e possivelmente pode ser benéfico em juntas que necessitem de tratamento térmico após a soldagem para alívio de tensões;

- Apesar do aquecimento localizado, as taxas calculadas por Rosenthal apresentam valores que mais se assemelham com o fenômeno real, provavelmente pela pequena largura da região pré-aquecida em relação à largura do cordão de solda. 


\section{Referências}

[1] British Standards Institution. BS EN 1011-2: 2001: welding recommendations for welding of metallic materials. Part 2: Arc welding of ferritic steels. London: BSI; 2001.

[2] El Rayes M, Walz C, Sepold G. The influence of various hybrid welding parameters on bead geometry. Welding Journal. 2004;83(Suppl 5):147S-153S.

[3] Aloraier A, Ibrahim R, Thomson P. FCAW process to avoid the use of post weld heat treatment. International Journal of Pressure Vessels and Piping. 2006;83(5):394-398. http://dx.doi. org/10.1016/j.ijpvp.2006.02.028.

[4] Jones J, Rhoades VL, Madden SK. High deposition welding for shipbuilding. In: National Shipbuilding Research Program. Joint Panel Meeting; 2012; Minneapolis. Minneapolis, MN, EUA, 2012. PPPF Panel. Paper No. P44.

[5] Jones J. Hybrid induction arc welding reduces weld distortion and boosts productivity. Advanced Materials \& Processes. 2015.

[6] Dutra WT, Machado IG, Gonzales AR. Soldagem a arco assistida por aquecimento indutivo localizado. In: Associação Brasileira de Soldagem. Anais do Congresso Nacional de Soldagem; 2016; Belo Horizonte, Brasil. São Paulo: ABS; 2016. p. 17-18.
[7] American Society for Testing and Material. ASTM A1005/ A1005M-00(2010): standard specification for steel line pipe, black, plain end, longitudinal and helical seam, double submerged-arc welded. West Conshohocken: ASTM; 2010. http://dx.doi.org/10.1520/A1005_A1005M-00R10.

[8] American Society of Mechanical Engineers. ASME B16.49-2000: factory made wrought steel buttwelding induction bends for transportation and distribution systems. Washington: ASME.

[9] Yurioka N, Kasuya T. A chart method to determine necessary preheat in steel welding. Welding in the World. 1995;35:327334.

[10] COMSOL Inc. COMSOL Multiphysics, versão 5.2: Heat Transfer Module. Suécia: COMSOL Inc.; 2015. Licença número 9100084 , versão para Windows.

[11] Rosenthal D. The theory of moving sources and its application to metal treatments. New York: ASME; 1946. p. 849-866. (Transactions of the ASME).

[12] Kirkaldy JS. Heat treating of steel. In: American Society for Metals. Metals handbook - Heat Treating. Metals Park, Ohio: ASM; 1995. Chap. 1. 